MagNetE workshop 2011

\title{
UK 2009-2010 repeat station report
}

\author{
Thomas J.G. Shanahan ${ }^{\star}$, Anthony P. Swan, Susan Macmillan
}

British Geological Survey, Edinburgh, United Kingdom

\author{
Article history \\ Received October 14, 2011; accepted February 15, 2012. \\ Subject classification: \\ Geomagnetism, Declination, Survey, Gyroscope.
}

\section{ABSTRACT}

The British Geological Survey is responsible for conducting the UK geomagnetic repeat station programme. Measurements made at the UK repeat station sites are used in conjunction with the three UK magnetic observatories: Hartland, Eskdalemuir and Lerwick, to produce a regional model of the local field each year. The UK network of repeat stations comprises 41 stations which are occupied at approximately 3-4 year intervals. Practices for conducting repeat station measurements continue to evolve as advances are made in survey instrumentation and as the usage of the data continues to change. Here, a summary of the 2009 and 2010 UK repeat station surveys is presented, highlighting the measurement process and techniques, density of network, reduction process and recent results.

\section{Introduction}

Every year a UK regional model of the magnetic field and its present and near-future rate of change is produced in conjunction with a fieldwork campaign of repeat station measurements across the UK. This model is applicable for the area of the British National Grid coordinate system and is typically used to service requests for magnetic north information received from a UK mapping agency. The primary source of data for this model is the repeat station network and UK magnetic observatories maintained by the British Geological Survey. In this paper we present the most recent model (OSMOD2011), which has been updated with measurements made in 2009 and 2010, when a total of 19 repeat stations were occupied over the two summer fieldwork campaigns (Figure 1).

The three geomagnetic observatories in the UK are located at Lerwick in Shetland, Eskdalemuir in Dumfries and Galloway, and Hartland in Devon (Figure 1). These observatories provide continuous absolute measurement of the magnetic field in the north eastern, central and south western areas of the country.

The equipment used for performing repeat station measurements is continually evolving as survey practices, technology, and instruments advance. In this paper we investigate the use of Global Positioning System (GPS) receivers for their suitability in making repeat station measurements - specifi- cally in determining true North information which has been typically measured using a north seeking gyroscope. Sun observations for true North, used frequently in other parts of Europe, are not a practical option in the UK due to the generally overcast weather conditions.

\section{UK Repeat Station Network}

Absolute measurements of the magnetic field are performed every 3-4 years at a selection of sites that make up the UK network of repeat stations. These sites are classified as 'first-order' repeat stations, using magnetic observatories for reduction of data to quiet time levels [Netwitt et al. 1996].

\section{Reduced number of stations}

At the end of the 2008 measurement campaign, we reduced the network of 51 repeat stations to 41 (Figure 1). We took this action to shorten the time between successive measurements at each site and to improve overall quality of measurements by eliminating sites with high levels of cultural noise. Long-term measurements of secular variation from the UK magnetic observatories (Figure 2) indicate that rate of change of declination (secular variation) is at levels that have not been seen since 1935. Since the focus of repeat station measurements is to capture the time-varying core field changes on a regional scale, shortening the time period between visits at individual sites (increasing the temporal sampling) supports this objective. The reduction in the density of the network (now near $100 \mathrm{~km}$ spacing on average, previously $70 \mathrm{~km}$ ) is not expected to impact the ability to discern the spatial changes associated with the main field as the wavelengths associated with the core field changes are typically in excess of $400 \mathrm{~km}$.

\section{Measurement process}

We locate repeat station sites initially by maps then, once on site, by site surveys and hand-held GPS with recorded waypoints. The measurement position is accurately marked by a stone slab buried in the ground. Locating the stone ensures the re-occupation position is to within $20 \mathrm{~cm}$, 


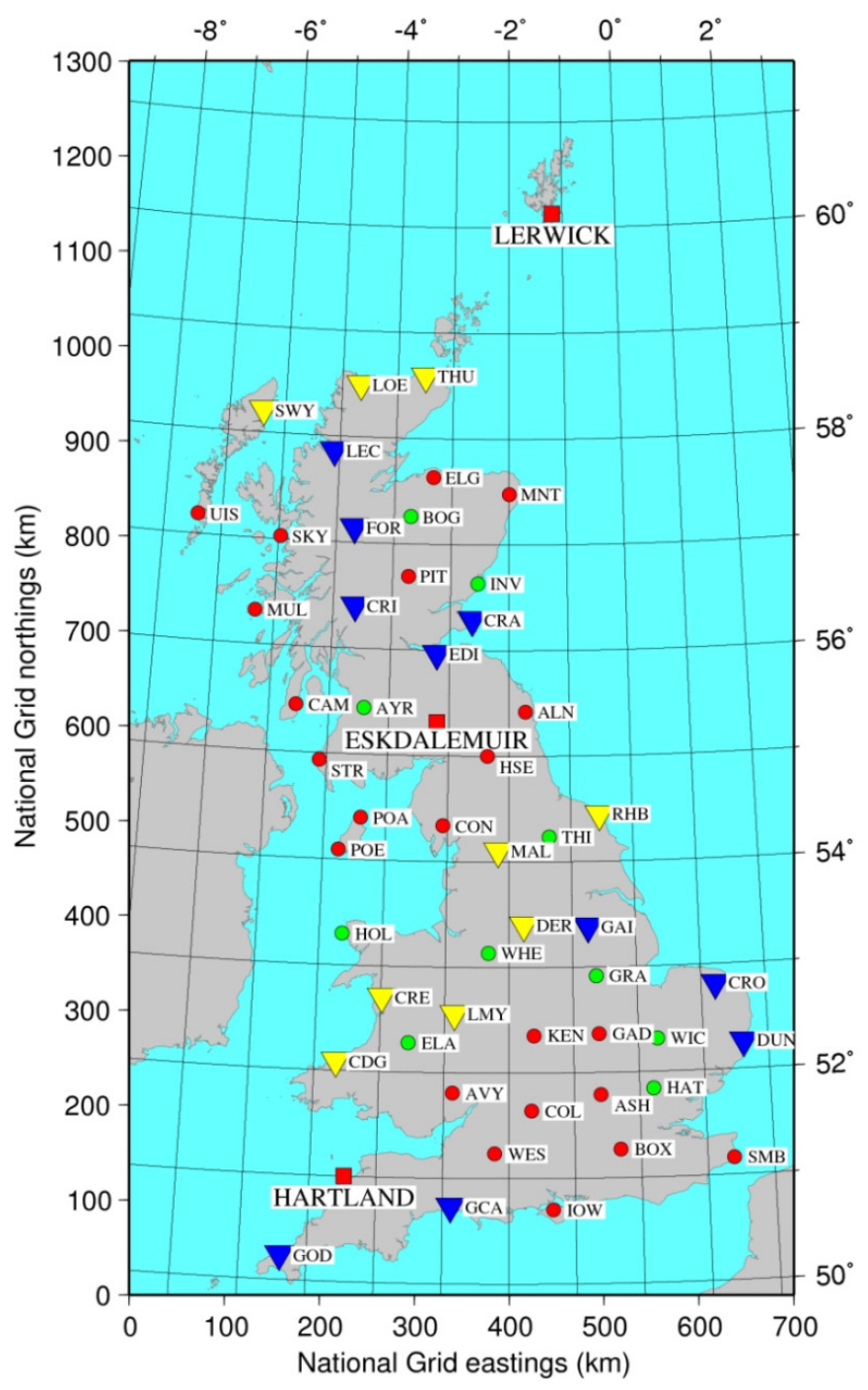

Figure 1. UK repeat stations visited in 2009 (yellow triangles) and 2010 (blue triangles), repeat stations removed in 2008 (green circles), repeat station visited prior to 2009 (red circles) and UK observatories (red squares).

which is close enough to guarantee the effect of any local crustal field variation is minimised.

To check for large crustal field anomalies or cultural contamination, a Proton Precession Magnetometer (PPM) survey is conducted to check that the local magnetic gradients are less than $1 \mathrm{nT} / \mathrm{m}$ over a $40 \mathrm{~m}$ grid centred on the observing position. A PPM records the total field variations during the period of the survey and is sampled at 1-minute intervals. These total field data are translated to the absolute observing position by performing a site-difference measurement where a second PPM is run in parallel at the absolute site and both are sampled at 10-second intervals for a period of at least 15 minutes.

True North (TN) is determined using either a northseeking gyroscope (Wild GAK1), calibrated at Eskdalemuir observatory before and after each field trip, or a differential GPS system (Leica GPS500). This process takes up to an hour to complete and produces a TN reference with an accuracy of around 10".
Eight absolute observations, carried out using a CarlZeiss Jena theodolite and Bartington Mag-01H fluxgate magnetometer combination (fluxgate-theodolite), are performed at regular intervals during the seven hours spent at the site. Each observation is based on the DI-Fluxgate-Theodolite Null-method using a non-magnetic tripod. All the instruments used are shown in Figure 3.

\section{Data reduction process}

Reduction of the raw repeat station measurements to a quiet level is carried out by reference to the two UK observatories closest in latitude to the station. In the case of stations south of Hartland only Hartland data is used. Quiet-time values are selected by examining data from the observatories for the eleven-day period centred on the observation day. The quiet night-time value for each observatory is taken to be the mean of the two hourly means either side of midnight from two days showing minimal external field disturbance. Nighttime values are used because the regular external variation is at a minimum at this time. Periods of minimal irregular external field disturbance are selected by examining the threehourly $\mathrm{K}$ indices from the reference observatories.

If an observation of magnetic field element $E$ is made at time $t$ then the final value of $E$, reduced to a quiet level, is calculated as follows:

where

$$
E_{q}(t, \text { station })=E(t, \text { station })+C
$$

$C=$

$\frac{\Delta \theta_{2}\left(E_{q}(t, o b s 1)-E(t, o b s 1)\right)+\Delta \theta_{1}\left(E_{q}(t, o b s 2)-E(t, o b s 2)\right)}{\theta_{1}-\theta_{2}}$

$\theta_{1}=$ latitude of the observatory north of the station $\theta_{2}=$ latitude of the observatory south of the station $\theta_{\mathrm{s}}=$ latitude of the station

$\Delta \theta_{1}=\theta_{1}-\theta_{\mathrm{s}}$ $\Delta \theta_{2}=\theta_{s}-\theta_{2}$

$E(t$, station $)=$ value of $E$ at the station at time $t$

$E(t, o b s 1)=$ value of $E$ at observatory- 1 at time $t$

$E(t, o b s 2)=$ value of $E$ at observatory-2 at time $t$

$E_{q}(t, o b s 1)=$ quiet level of $E$ at observatory- 1 at time $t$ $E_{q}(t, o b s 2)=$ quiet level of $E$ at observatory-2 at time $t$.

Once the data are reduced to quiet-time levels they are then reduced to epoch (e.g., 2010.5). This is done using an annual model of the secular variation for each component, derived from data collected at observatories in western Europe and at the repeat stations. The final results for each site are based on a simple average of all the observations (reduced to quiet time). If any observation is considered an out- 


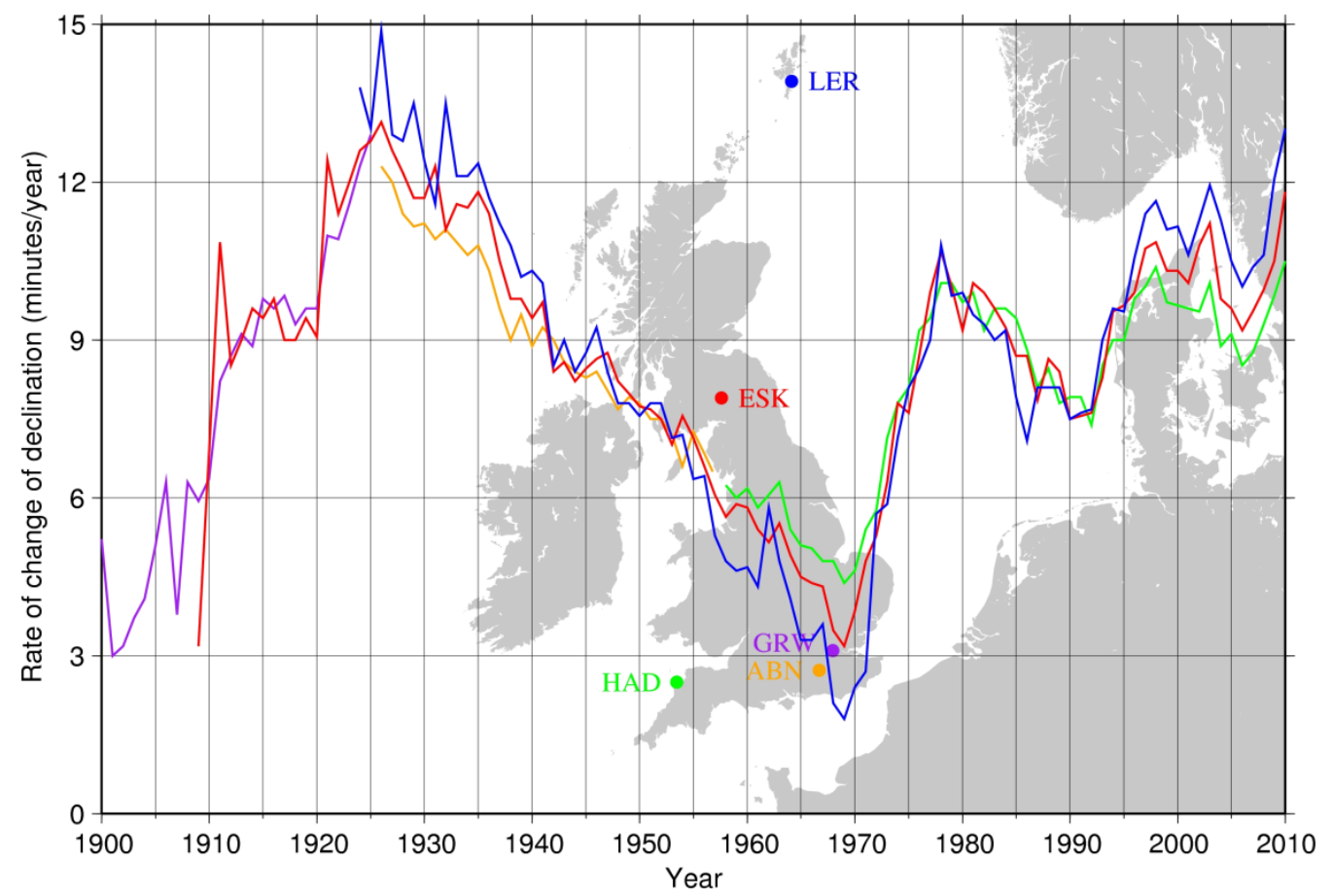

Figure 2. Change in secular variation (declination) from UK observatories.

lier or the collimation errors are large then it will not be included in the averaging process.

\section{Results for 2009 and 2010 surveys}

The results for the 2009 and 2010 repeat station surveys are summarised in Table 1 and Table 2 [Shanahan and Macmillan 2010]. These data are online from the global repeat station holdings maintained by BGS (www.geomag.bgs.ac.uk).
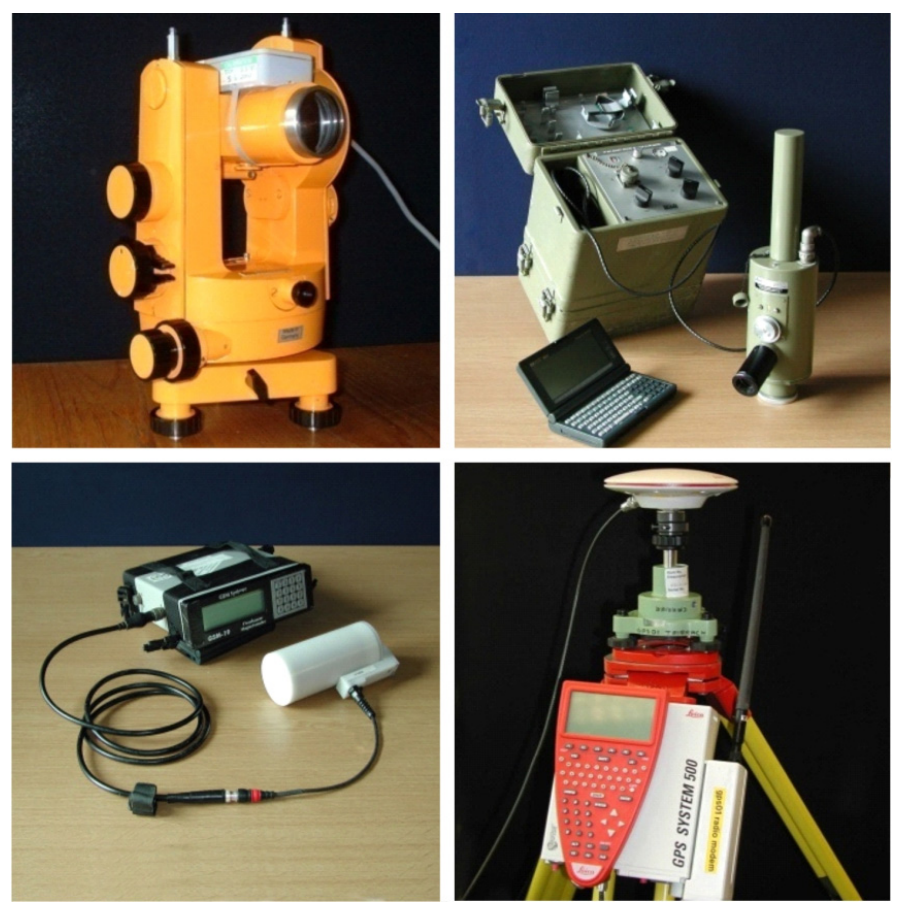

Figure 3. Survey instrumentation (clockwise: fluxgate-theodolite, gyroscope, GPS and PPM).
These values represent the final results after the process of reduction to quiet time. Contour plots of declination, rate of change of declination, inclination and total field, derived from the new 2010 model, are presented in Figure 4.

\section{Differential GPS for true North measurement}

For the majority of repeat station campaigns, the North seeking gyroscope has been employed for determination of true North - required for declination measurements. More recently, the use of a Leica GPS500 differential GPS has become an attractive alternative to the gyroscope due to a number of benefits [Carrigan 2002]. The GPS system is a more rugged system that is easier to transport and less sensitive to environmental conditions. We found the GPS measurement process is less susceptible to operator error, faster than a gyroscope at mid and low latitudes, and also provides an effective mechanism for very accurate recording of the site location (when used in conjunction with a national network of GPS base stations as an absolute reference). Before adopting the use of the GPS system for fieldwork measurements, we carried out a comparison of the two instruments at Eskdalemuir magnetic observatory to better quantify the typical errors associated with the different techniques for determining true North.

\section{GPS background}

The GPS satellites broadcast two carrier waves: the L1 carrier at $1575.42 \mathrm{MHz}$; and the L2 carrier at $1227.60 \mathrm{MHz}$. Modulated on these two carrier frequencies are much lower frequency codes referred to as code phase which is a pseudo-random code used for matching satellite and re- 


\begin{tabular}{|c|c|c|c|c|c|c|}
\hline Station & $\begin{array}{c}\text { Measurement } \\
\text { date (years) }\end{array}$ & $\begin{array}{l}\text { Latitude } \\
\text { (degrees) }\end{array}$ & $\begin{array}{l}\text { Longitude } \\
\text { (degrees) }\end{array}$ & $\begin{array}{l}\text { Declination } \\
\text { (degrees) }\end{array}$ & $\begin{array}{l}\text { Inclination } \\
\text { (degrees) }\end{array}$ & $\begin{array}{l}\text { Total field } \\
\text { (nT) }\end{array}$ \\
\hline Cardigan Bay & 2009.667 & 52.089 & -4.667 & -3.395 & 66.940 & 48681 \\
\hline Long Mynd & 2009.670 & 52.555 & -2.850 & -2.967 & 67.327 & 48752 \\
\hline Cregennan & 2009.673 & 52.708 & -3.984 & -3.479 & 67.233 & 48888 \\
\hline Stornoway & 2009.722 & 58.210 & -6.395 & -6.466 & 71.452 & 50321 \\
\hline Loch Eriboll & 2009.727 & 58.497 & -4.667 & -4.789 & 71.639 & 50548 \\
\hline Thurso & 2009.730 & 58.588 & -3.501 & -4.293 & 71.648 & 50381 \\
\hline Derwent Estate & 2009.571 & 53.400 & -1.765 & -2.671 & 67.954 & 49105 \\
\hline Malham & 2009.574 & 54.104 & -2.175 & -2.913 & 68.470 & 49269 \\
\hline Robin Hoods Bay & 2009.577 & 54.444 & -0.531 & -2.484 & 68.755 & 49362 \\
\hline
\end{tabular}

Table 1. 2009 repeat station results (reduced to quiet time).

\begin{tabular}{|c|c|c|c|c|c|c|}
\hline Station & $\begin{array}{c}\text { Measurement } \\
\text { date (years) }\end{array}$ & $\begin{array}{l}\text { Latitude } \\
\text { (degrees) }\end{array}$ & $\begin{array}{l}\text { Longitude } \\
\text { (degrees) }\end{array}$ & $\begin{array}{l}\text { Declination } \\
\text { (degrees) }\end{array}$ & $\begin{array}{l}\text { Inclination } \\
\text { (degrees) }\end{array}$ & $\begin{array}{l}\text { Total field } \\
\text { (nT) }\end{array}$ \\
\hline Lecmelm & 2010.771 & 57.862 & -5.094 & -4.632 & 71.158 & 50459 \\
\hline Fort Augustus2 & 2010.571 & 57.140 & -4.684 & -4.242 & 70.721 & 50250 \\
\hline Crianlarich & 2010.574 & 56.403 & -4.625 & -4.498 & 70.007 & 49734 \\
\hline Crail & 2010.760 & 56.291 & -2.626 & -3.106 & 70.021 & 49802 \\
\hline Edinburgh & 2010.492 & 55.965 & -3.217 & -3.671 & 69.801 & 49788 \\
\hline Gainsborough & 2010.651 & 53.385 & -0.747 & -2.112 & 67.923 & 49156 \\
\hline Cromer & 2010.648 & 52.813 & 1.225 & -1.458 & 67.589 & 48968 \\
\hline Dunwich Heath & 2010.645 & 52.255 & 1.621 & -1.198 & 67.149 & 48834 \\
\hline Stonebarrow & 2010.821 & 50.735 & -2.879 & -2.493 & 65.715 & 48314 \\
\hline Godrevy Point & 2010.818 & 39.763 & -5.393 & -3.307 & 65.220 & 48112 \\
\hline
\end{tabular}

Table 2. 2010 repeat station results (reduced to quiet time).

ceiver signals for measurement of range. This code also contains information about the satellite, including an accurate position. As the code phase has a relatively large period the calculated position can be in error by several metres. Much greater positional accuracy can be achieved by additionally using the carrier phase for synchronisation, which has a frequency 1000 times greater than code phase. The most sophisticated receivers use the code phase to get an approximate position and then the carrier phase to get a much more accurate position. This method is used by survey grade receivers (e.g., Leica GPS500) which have a positional accuracy of around $10 \mathrm{~cm}$ or better. Positional errors can occur due to the refraction effects of the iono- sphere and the troposphere, which is the reason two carrier frequencies are useful. A technique called Differential GPS involves twin receivers (less than $20 \mathrm{~km}$ apart); the base receiver is installed at an accurately known position and records the apparent location error, which is used to correct the remote receiver which is tracking the same satellites. Thus any error which is common to both receivers is accounted for yielding relative positional accuracies, between the two receivers, of as little as a few millimetres. By using the two receivers' positions as a baseline, a very accurate azimuth can be determined for the remote receiver which can then act as a reference for declination measurements. 

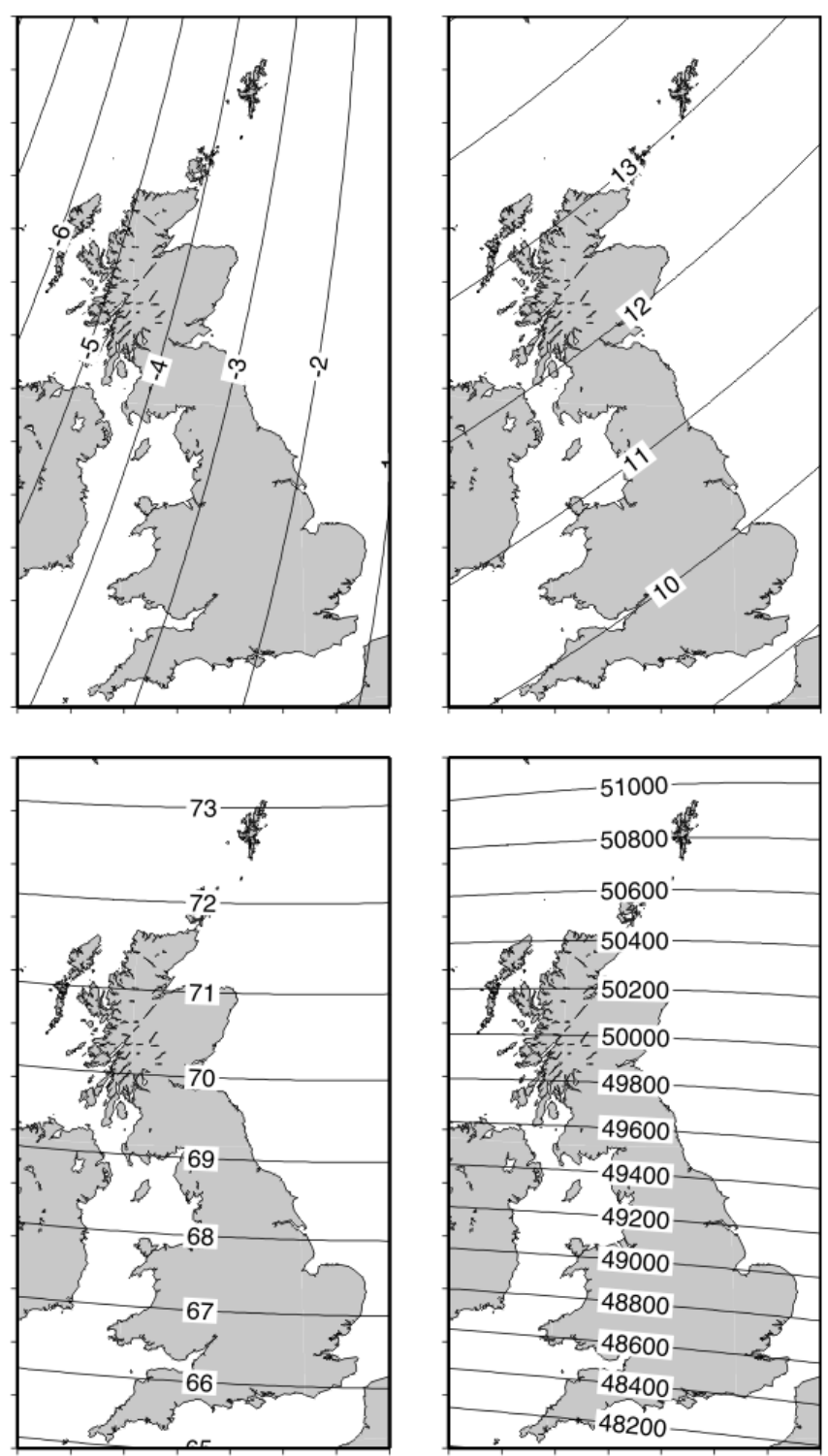

Figure 4. Clockwise: declination, rate of change of declination, total field and inclination for 2010.5.

\section{Comparison of gyroscope and GPS}

To compare the two survey instruments, the Eskdalemuir observatory fixed mark, used for absolute observations, was used as an established baseline azimuth to validate the results. Azimuth determination using the gyroscope was directly carried out by conducting a standard gyroscope observation on the observatory pillar.

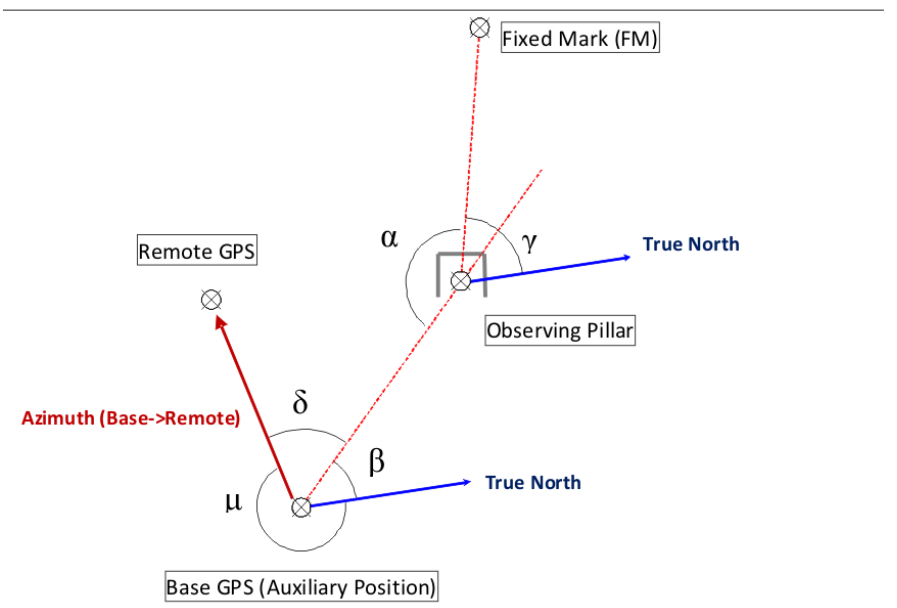

Figure 5. Fixed mark measurement using base GPS station on auxiliary position.

To measure the azimuth of the fixed mark using the differential GPS, a base station and a remote station are run concurrently over a period of at least half an hour. The base and remote stations were separated by approximately $120 \mathrm{~m}$. Since the observatory observing pillar is located in a covered building, the GPS base station needed to be located at an auxiliary site to allow a clear view of the sky whilst still remaining in site of the observing pillar (Figure 5).

Post processing of the GPS data for both stations, using the same satellites, produced a relative position for the remote station with a standard deviation of less than $2 \mathrm{~mm}$ and an azimuth bearing for the remote station $(\mu)$. A theodolite was then precisely located on the GPS base station tripod and used to measure the angle from the remote station (through the open doorway) to the observing pillar $(\delta)$. Locating the theodolite on the observatory pillar then allowed measurement of the angle between the fixed mark and the GPS base station $(\alpha)$. Finally, calculation of the angle $\beta$ then enables the fixed mark azimuth $(\gamma)$ to be determined from the simple equation:

$$
\begin{aligned}
& \gamma=\beta+180-\alpha \\
& \text { and: } \beta=360-(\mu+\delta) \\
& \text { so: } \gamma=[360-(\mu+\delta)]+(180-\alpha)
\end{aligned}
$$

Instrument

Date

\section{Baseline azimuth (degrees)}

\section{Measured azimuth (degrees)}

Difference

(arc-seconds)

\begin{abstract}
Leica Differential GPS500
\end{abstract}
Wild GAK-1 Gyroscope
09/06/2011

$09 / 06 / 2011$
188.2097

188.2097
188.2038

Table 3. Comparison of azimuth determination for Wild GAK-1 gyroscope and Leica GPS500. 
The results of the two different instruments are summarised in Table 3. The difference between the two measurements is extremely small ( 1 arc-second) and the absolute error in measurement from the established baseline for both instruments ( $\sim 20$ arc-seconds) would perhaps indicate that the baseline azimuth is in error rather than the instruments azimuths.

\section{Conclusions}

The data collected during the 2009 and 2010 repeat station measurement campaigns have been used to produce an updated regional magnetic field model of declination, Inclination and total field strength for the UK. This model will be used primarily to provide current and future estimates of the magnetic field components and their rates of change for the period 2010.5 to 2013.5. Since the spatial density of the repeat station network was reduced in 2008 (by approximately $20 \%$ ), the time period between reoccupation of sites in the UK has been significantly reduced. This change has been well suited to capturing the time varying changes of the core field which have been at their highest levels since 1935 .

Our comparison of the gyroscope and differential GPS for true North measurements clearly demonstrated the potential for differential GPS to serve as a viable alternative to the gyroscope, whilst still maintaining a very high level of accuracy in the final result. Due to the additional benefits of using a GPS system, it is anticipated that use of this system will become the standard practice for true North measurements at UK repeat stations in the future.

\section{References}

Carrigan, J.G. (2002). A Review of Methods to Determine True North for Measurement of Declination, In: Proceedings of the $X^{\text {th }}$ Workshop on Geomagnetic Observatory Instruments, Data Acquisition and Processing, Hermanus, April 2002.

Newitt, L.R., C.E. Barton and J. Bitterly (1996). Guide for Magnetic Repeat Station Surveys, International Association of Geomagnetism and Aeronomy, ISBN: 0-96506861-7.

Shanahan, T.J.G., and S. Macmillan (2010). Provision of Magnetic North Information to the Ordnance Survey - 2010 Annual Report, British Geological Survey Commissioned Report, CR/10/139, 35 pp.

\footnotetext{
${ }^{\star}$ Corresponding author: Thomas J.G. Shanahan, British Geological Survey, Edinburgh, United Kingdom; email: tjgs@bgs.ac.uk. 